\title{
Bio-molecular Diagnosis of Avian Influenza Virus from Different Species of Birds in Bangladesh
}

\author{
Mohammed Hafizur Rahman ${ }^{1}$, Mohammed Giasuddin ${ }^{1, *}$, Mohammed Rafiqul Islam ${ }^{2}$, Mahmudul Hasan ${ }^{1}$, \\ Mohammad Showkat Mahmud ${ }^{1}$, Mohammed Ahsanul Hoque ${ }^{3}$, Paritosh Kumar Biswas ${ }^{3}$, \\ Emdadul Haque Chowdhury ${ }^{2}$, Bidhan Chandra Das ${ }^{4}$, Mohammed Ziaur Rahman $^{5}$, \\ Nitish Chandra Debnath ${ }^{6}$, Garba Ahmed ${ }^{6}$, Mat Yamage ${ }^{6}$ \\ ${ }^{1}$ Animal Health Research Division,Bangladesh Livestock Research Institute, Savar, Dhaka1341, Bangladesh \\ ${ }^{2}$ Department of Pathology, Faculty of Veterinary Science, Bangladesh Agricultural University, Mymensingh-2202, Bangladesh \\ ${ }^{3}$ Chittagong Veterinary and Animal Science University, Chittagong, Bangladesh \\ ${ }^{4}$ Central Disease Investigation Laboratory, Department of Livestock Services, Dhaka, Bangladesh \\ ${ }^{5}$ International Centre for Diarrhoeal Disease Research, Bangladesh (ICDDR,B), Mohakhali, Dhaka, Bangladesh \\ ${ }^{6}$ Food and Agricultural Organization, Bangladesh
}

Copyright (C) 2015 Horizon Research Publishing All rights reserved.

\begin{abstract}
Highly pathogenic avian influenza (HPAI) causes enormous losses to the poultry industry of Bangladesh every year since the detection of first outbreak in 2007. In this study biomolecular diagnosis of avian influenza virus in Bangladesh from different species of birds was carried. A total of 1135 samples including 280 from migratory birds, 680 from live bird market (LBM) chickens, 118 from ducks and 57 from pigeons were collected from different locations of Bangladesh during the period from July 2013 to June 2014. Out of 1135 samples, 69 were found positive for influenza A by real time RT-PCR. In addition, 741 Influenza A positive samples collected by different institutes from different species of birds under the FAO-led surveillance program were also received at Bangladesh Livestock Research Institute (BLRI) for further analysis. The real time RT-PCR positive samples were inoculated in 10-day-old embryonated chicken eggs. Out of $810(741+69)$ influenza A positive samples, 110 were selected on the basis of species and region to cover the whole country and were sent to the OIE reference laboratory for detailed study. The bio-molecular results revealed that in case of migratory bird samples one was H5 (HPAI), two were H9 and eight were of undetermined subtype. Among the LBM chicken samples, seven were H5 (HPAI), 51 were H9, six were mixed infection with $\mathrm{H} 5$ \& $\mathrm{H} 9$ and three were of undermined subtype. In case of duck samples, one was $\mathrm{H} 2$, six were $\mathrm{H} 4$, six were $\mathrm{H} 5$ (HPAI), one with mixed infection with $\mathrm{H} 5$ \& $\mathrm{H} 2$, one with both H5 \& H4, two were H9 and one was H7N5, though $\mathrm{H} 7$ was genetically distinct from that of the novel H7N9 virus of China. Among quail samples, one was H5 (HPAI) and one was H9. In case of pigeon samples, all three contained H9. From this study it was revealed that HPAI (H5N1) is still circulating in our poultry population. The novel avian influenza virus H7N9 was not found during this study.
\end{abstract}

Keywords Avian Influenza, Surveillance, Real Time RT-PCR, Bangladesh

\section{Introduction}

Avian influenza virus has received increasing attention over the years, as it affects poultry production, trade and human health. The viruses are distributed worldwide and cause serious economic losses when outbreaks occur in chickens, turkeys, and other gallinaceous birds. Migrating wild waterfowl are assumed to represent a risk for the transmission of avian influenza virus to poultry and cause serious economic losses [1,2]. Most of the avian influenza viruses replicate preferentially in the gastrointestinal tract of wild ducks, are excreted at high levels in feces, and are transmitted through the fecal-oral route [3].

In Bangladesh HPAI H5N1 was first detected in March 2007 near the capital city of Dhaka by National Reference Laboratory for Avian Influenza (NRL-AI) [4]. Then this disease spread to at least 51 of the country's 64 districts and has become endemic in poultry of Bangladesh. Seven human cases with one case fatality by H5N1 virus in Bangladesh have been reported to WHO. Bangladesh has a long border with India and Myanmar. Moreover, during the winter (December-February), open water bodies in Bangladesh are shared by large number of migratory waterfowl and domestic semi-scavenging ducks. As a result, the domestic ducks might get avian influenza viruses (AIVs) from migratory waterfowls, which may act as a natural reservoir of AIVs without showing clinical disease. In Bangladesh households keep chickens and ducks on same premises with poor biosecurity [5] and domestic semi-scavenging ducks are often in close contact with poultry, livestock, and humans in 
the same property. Therefore, domestic ducks may play a major role in the ecology of AIVs in Bangladesh and may act as potential vessels for their genetic reassortment [5]. From 2011 it was observed that introduction of two new clades 2.3.2.1 and 2.3.4 viruses into Bangladesh in addition to clade 2.2 viruses. But since 2012 clade 2.2 viruses are being replaced by clades 2.3.2.1 virus [6,7]. It has been established that migratory birds are playing important role in introduction of new clades of viruses [8]. In this regards active surveillance of avian influenza viruses from different species of poultry and their characterization may give an idea about circulating avian influenza viruses in this country.

\section{Materials and Methods}

\subsection{Sample Collection}

A total of 1135 samples including 280 environmental fecal samples from migratory birds, 680 swabs samples from LBM chickens, 118 swabs samples from native ducks and 57 swab samples from pigeons were collected randomly during the period from July 2013 to June 2014 from different locations of Bangladesh and transported to the National Reference Laboratory for Avian Influenza, BLRI.

\subsection{Sample Processing}

RNA was extracted and real time RT-PCR was performed for influenza A virus matrix gene using specific primers: Forward primer $(\mathrm{M}+25) 5^{\prime}$-AGA TGA GTC TTC TAA CCG AGG TCG-3'; Reverse primer (M-124) 5'-TGC AAA AAC ATC TTC AAG TCT CTG-3' and probe: $(\mathrm{M}+64)$ 5' - FAM-TCA GGC CCC CTC AAA GCC GA-TAMRA-3' following the method [9]. Surveillance samples were pooled (1:5 ratio) for initial screening. All samples of a positive pool were then tested individually for identifying the individual positive samples.

\subsection{Influenza A positive samples from other laboratories}

About 741 Influenza A positive samples were received by NRL-AI from a FAO program consisting 05 samples from the Department of Pathology of Bangladesh Agricultural University (BAU), 34 samples from CDIL, 656 from the International Centre for Diarrhoeal Disease Research,
Bangladesh (icddr,b) and 46 from Chittagong Veterinary and Animal Sciences University (CVASU) for further analysis. These samples had been collected from different species including chickens, ducks, pigeons and quails from different areas of Bangladesh under the FAO-led surveillance program in the year of 2013 .

\subsection{Virus Isolation and Identification}

Real time RT-PCR positive samples were inoculated in ten days old embryonated chicken eggs through allantoic route. Eggs were incubated at $37^{\circ} \mathrm{C}$ for $48-72$ hours. Allantoic fluid was harvested from eggs after death of the embryos or at the end of the incubation period. Allantoic fluid was subjected to haemagglutination (HA) test. The HA positive sample was further tested by the RT-PCR for confirmation of AI virus using specific primer sets from published literature [9]. One hundred ten (110) representative influenza A positive samples were selected on the basis of species and region to cover the whole country and were sent to the OIE reference laboratory, Padova, Italy for further detailed study. OIE Reference laboratory used the method for diagnosis of avian influenza virus by real time RT-PCR using the specific primers and probes sets against influenza A matrix gene, H5, H9 and $\mathrm{H} 7$ gene of avian influenza virus.

\section{Results}

The repeated introductions of $\mathrm{H} 5 \mathrm{~N} 1$ virus into Bangladesh since 2007 [10] and recent outbreaks of H7N9 virus in China have indicated the need for monitoring the migratory birds, domestic ducks, poultry population and other avian species for AIVs.Therefore, environmental feces samples from migratory birds, cloacal and oropharyngeal swabs samples from native scavenging ducks, quails and domestic pigeons were collected and screened during this study. Out of 1135 surveillance samples 69 were positive for both HA test and influenza virus A specific real time RT-PCR (Table 1).

The representative 110 influenza A positive samples were selected from 810 influenza A positive samples (741 from other laboratories and 69 from surveillance samples of NRL-AI) and sent to the OIE reference laboratory for further detail study. The results are presented in Table 2 .

Table 1. Isolation and identification of AI virus from surveillance samples of NRL-AI

\begin{tabular}{ccccc}
\hline Species & No. of samples & $\begin{array}{c}\text { No. of isolates with HA } \\
\text { activity }\end{array}$ & $\begin{array}{c}\text { No. of isolates positive for } \\
\text { influenza virus A by real time } \\
\text { RT-PCR }\end{array}$ & $\begin{array}{c}(\%) \\
\text { positive }\end{array}$ \\
\hline Migratory bird & 280 & 11 & 11 & 3.93 \\
LBM chickens & 680 & 48 & 48 & 7.06 \\
Duck & 118 & 7 & 7 & 6.0 \\
Pigeon & 57 & 3 & 3 & 5.26 \\
\hline Total & 1135 & 69 & 69 & 6.19 \\
\hline
\end{tabular}


Table 2. Bio-molecular results of OIE reference Laboratory, Italy

\begin{tabular}{|c|c|c|c|c|c|c|c|c|c|c|}
\hline \multirow[b]{2}{*}{ Species } & \multicolumn{10}{|c|}{ Test Results } \\
\hline & $\begin{array}{c}\text { Influenza } \\
\mathrm{A}^{*}\end{array}$ & $\mathrm{H} 2$ & $\mathrm{H} 4$ & H5 & H5\& H2 & H5 \& H4 & H5 \& H9 & H7N5 & H9 & Total \\
\hline Migratory bird & 05 & - & - & 01 & - & - & - & - & 02 & 08 \\
\hline LBM chickens & 03 & - & - & 07 & - & - & 06 & - & 51 & 67 \\
\hline Duck & 12 & 01 & 06 & 06 & 01 & 01 & - & 01 & 02 & 30 \\
\hline Quail & - & - & - & 01 & - & - & - & - & 01 & 02 \\
\hline Pigeon & - & - & - & - & - & - & - & - & 03 & 03 \\
\hline Total & 20 & 01 & 06 & 15 & 01 & 01 & 06 & 01 & 59 & 110 \\
\hline
\end{tabular}

* Subtype not determined

\section{Discussion}

From this study it is revealed that in migratory birds samples one was positive for H5 (HPAI), two for LPAI (H9) and five were of undetermined subtype. H5 HPAI virus was isolated earlier from migratory birds [8] and crows [10] in Bangladesh.

In LBM chicken samples 51 were H9 (LPAI), seven were H5 (HPAI), six were mixed infection with H5 \& H9 and three were of undetermined subtype. LPAI was the predominant AI strain circulating in the live bird market in Bangladesh. This report is comparable to the recent prevalence reporton live bird market in Bangladesh, including other Asian countries such as Iran and Pakistan $[11,12]$. In case of duck samples, one had $\mathrm{H} 2$, six had $\mathrm{H} 4$, six had H5 (HPAI), one had mixed infection with $\mathrm{H} 5 \& \mathrm{H} 2$, one had both $\mathrm{H} 5$ \& H4, 02 had H9. In this study one duck sample was $\mathrm{H} 7 \mathrm{~N} 5$. However, $\mathrm{H} 7$ gene of this isolate was genetically distinct from that of the novel H7N9 virus of China.The LPAI H2, H4 and $\mathrm{H} 7$ are the most common subtypes of wild waterfowl in North America [13].

Influenza viruses of several subtypes have been isolated from quails in Asia [14]. From 2011, deaths due to HPAI infection were reported in quails and ducks [6]. In this study it is revealed that among the quail samples, one had H5 (HPAI) and one had H9.In pigeon samples, all three samples contained H9 subtypes as reported elsewhere $[15,16]$. They isolated the LPAI (H9N2) viruses from healthy pigeons in South Africa.

The high prevalence of AI H9N2 in poultry market may provide the opportunity of human infections and the possibility of reassortment with the existing poultry AI viruses including HPAI H5N1 [17]. This study underlines the need of continuous active surveillance in wild, migratory birds and in poultry.

\section{Conclusions}

From this study it was revealed that HPAI (H5N1) is still circulating in our poultry population and no novel avian influenza virus H7N9 was found during this study. The results of our study emphasize the need of continuous surveillance activities in Bangladesh that would allow detection of any newly emerged AIV with pandemic potential.

\section{REFERENCES}

[1] R. G. Webster, M. Peiris, H. Chen, Y. Guan. H5N1 outbreaks and enzootic influenza. Emerg Infect Dis, 12, 3-8, 2006.

[2] C. M. Jonassen, K. Handeland. Avian influenza virus screening in wild waterfowl in Norway, 2005. Avian Dis, 51, 425-428, 2007.

[3] K. M. Sturm-Ramirez, T. Ellis, B. Bousfield, L. Bissett, K. Dyrting, J. E. Rehg, L. Poon, Y. Guan, M. Peiris, R. G. Webster. Reemerging H5N1 influenza viruses in Hong Kong in 2002 are highly pathogenic to ducks. J Virol, 78, 48924901, 2004.

[4] J. Alam, M. Giasuddin, M. A. Samad, M. J. F. A. Taimur. Recent evidence of Avian Influenza in Bangladesh: a review. World's Poult Sci J, 66, 455-464, 2010.

[5] S. S. Ahmed, A. K. Ersboll, P. K. Biswas, J. P. Christensen, A. S. Hannan, N. Toft. Ecological determinants of highly pathogenic avian influenza (H5N1) outbreaks in Bangladesh. PLoS One 7, e33938, 2012.

[6] M. R. Islam, M. E. Haque, M. Giasuddin, E. H. Chowdhury, M. A. Samad, R. Parvin, M. Nooruzzaman, M. M. Rahman, P. Monoura. New Introduction of Clade 2.3.2.1 Avian Influenza Virus (H5N1) into Bangladesh. Transbound Emerg Dis, 59, 460-463, 2012.

[7] M. E. Haque, M. Giasuddin, E. H. Chowdhury, M. R. Islam. (2014) Molecular evolution of H5N1 highly pathogenic avian influenza viruses in Bangladesh between 2007 and 2012. Avian Pathol, 43, 183-194, 2014.

[8] R. Parvin, K. Heenemann, M. Y. Halami, E. H. Chowdhury, M. R. Islam, T. W. Vahlenkamp. Full-genome analysis of avian influenza virus H9N2 from Bangladesh reveals internal gene reassortments with two distinct highly pathogenic avian influenza viruses. Archives of Virol, 159, 1651-1661, 2014a.

[9] E. Spackman, A. Dennis, T. J. Senne, Myers, L. Leslie, Bulaga, P. Lindsey, Garber, L. Michael, Perdue, L. Kenton, T. Luke, Daum, L. S. David. Development of a Real-Time Reverse Transcriptase PCR Assay for Type A Influenza Virus and the Avian H5 and H7 Hemagglutinin Subtypes. J Clin Microbiol, 40, 3256-3260, 2002. 
[10] M. Giasuddin, A. Jahangir, M. A. Samad, P. Monoura, M. H. Al-Faruque, M. J. F. A. Taimur. Outbreak frequency of circulating strains of avian influenza virus in Bangladesh from 2007-2008. Proceedings of the 7th International Poultry Show and Seminar, Dhaka, Bangladesh, 63-68, 2011.

[11] N. J. Negovetich, M. M. Feeroz, L. Jones-Engel, D. Walker, S. M. Alam, K. Hasan, P. Seiler, A. Ferguson, K. Friedman, S. Barman. Live bird markets of Bangladesh: H9N2 viruses and the near absence of highly pathogenic H5N1 influenza. PLoS One, 6, e19311, 2011.

[12] K. Shanmuganatham, M. M. Feeroz, L. Jones-Engel. Antigenic and molecular characterization of avian influenza A(H9N2) viruses, Bangladesh. Emerg Infect Dis, 19, 1393 1402, 2013.

[13] K. K. Vandalen, A. B. Franklin, N. L. Mooers, H. J. Sullivan, S. A. Shriner. Shedding light on avian influenza H4N6 infection in mallards: modes of transmission and implications for surveillance. PloS One, 20, e12851, 2010.

[14] Y. J. Guo, S. Krauss, D. A. Senne, I. P. Mo, K. S. Lo, X. P. Xiong, M. Norwood, K. F. Shortridge, R. G. Webster, Y. Guan. Characterization of the pathogenicity of members of the newly established H9N2 influenza virus lineages in Asia. Virology, 267, 279-288, 2000.

[15] C. Abolnik. A current review of avian influenza in pigeons and doves (Columbidae). Vet Microbiol, 170, 181-96, 2014.

[16] S. M. Mansour, R. M. Melbakrey, H. Ali, D. E. Knudsen, A. A. Eid. Natural infection with highly pathogenic avian influenza virus $\mathrm{H} 5 \mathrm{~N} 1$ in domestic pigeons (Columba livia) in Egypt. Avian Pathol, 20, 1-6, 2014.

[17] I. Monne, M. Yamage, G. Dauphin, F. Claes, G. Ahmed, M. Giasuddin, A. Salviato, S. Ormelli, F. Bonfante, A. Schivo, G. Cattoli. Reassortant Avian Influenza A (H5N1) Viruses with H9N2-PB1 Gene in Poultry, Bangladesh. Emerg Infect Dis, 19, 1630-1634, 2013. 